\title{
Is "Movember" an Effective Prostate Cancer Awareness Campaign Beyond the English Language? Insights From Google Trends Among Spanish Speakers
}

\author{
Daniel A. González-Padilla, ${ }^{凶 1}$ Rodrigo España-Navarro, ${ }^{2}$ José Daniel Subiela, ${ }^{3}$ Raj Kumar, ${ }^{4}$ \\ Luis G. Medina, ${ }^{4}$ Júlia Aumatell, ${ }^{5}$ José Manuel De la Morena-Gallego, ${ }^{1}$ Giovanni E. Cacciamani ${ }^{4}$ \\ ${ }^{1}$ Department of Urology, University Hospital Infanta Sofía, Madrid, Spain ${ }^{2}$ Department of Urology, Regional University Hospital, Málaga, Spain \\ ${ }^{3}$ Department of Urology, University Hospital Ramón y Cajal, Madrid, Spain ${ }^{4}$ USC Institute of Urology and Catherine and Joseph Aresty Department of \\ Urology, Keck School of Medicine, University of Southern California, Los Angeles, United States ${ }^{5}$ Fundació Puigvert, Barcelona, Spain
}

\begin{abstract}
Objective To evaluate the impact of the "Movember" awareness campaign (men's health campaign that takes place every November) on internet search trends for information online about prostate cancer and to compare the results with those for "Pinktober" (the breast cancer awareness campaign that takes place in October) in the Spanish language as an indirect measure of its effectiveness.
\end{abstract}

Methods Google Trends was used to evaluate the monthly relative search volumes (RSV) of the terms "cáncer de próstata" (prostate cancer), "cáncer de mama" (breast cancer), and "Movember" from January 2009 to December 2019 both in Spain and worldwide (in the Spanish language). Breast cancer was used as a comparator of the campaign impact. Mean increase in RSV on-campaign and off-campaign was calculated and compared using the MannWhitney $\mathrm{U}$ test and Joinpoint regression analysis to assess loss or gain of interest.

Results The term "cáncer de próstata" showed a statistically significant increase during the campaign months both in Spain $(17.4 \% ; P<0.001)$ and worldwide $(35.4 \% ; P<0.001)$. Both "cáncer de próstata" and Movember showed a decreasing trend worldwide and in Spain, while "cáncer de mama" showed an increasing trend.

Conclusion The Movember campaign generates a statistically significant increase in the search trends on "cancer de próstata" (prostate cancer) during the month of November (both in Spain and worldwide); when compared with the breast cancer campaign "Pinktober" these increases are of a lesser magnitude but still significant, suggesting that the campaign is effective beyond the English language, although the interest has been decreasing throughout the years.

\section{Introduction}

Prostate cancer is the second most frequently diagnosed neoplasm in men and causes $3.8 \%$ of all cancer deaths worldwide[1]. In Spain, $89.8 \%$ of patients are diagnosed in the localized stage, $6.4 \%$ in the locally advanced, and only $3.8 \%$ in the metastatic stage[2].

The awareness campaign of men's health that is celebrated every November with a blue ribbon as a symbol, also known as "Movember," was started in Australia in 2003, aiming to increase awareness about prostate cancer, testicular cancer, mental health, and suicide prevention[3].

\section{Key Words}

Prostate cancer, awareness, Movember, Google Trends, breast cancer, Pinktober

\section{Competing Interests}

None declared.

\section{Article Information}

Received on June 9, 2021

Accepted on September 8, 2021

Soc Int Urol J.2021;2(6):362-369

DOI: https://doi:10.48083/UHSI5324 


\section{Abbreviations}

AAPC average annual percentage in change

APC annual percentage in change

ARSV annual RSV

RSV relative search volume

"Pinktober" is the breast cancer equivalent of Movember, held every October. Using a pink ribbon as a symbol, this campaign has been effective in encouraging women to get informed about breast cancer and in becoming part of an early detection program[4].

Although these campaigns receive strong support from governments and non-governmental organizations, the true impact of the Movember campaign in terms of public health is not well-known. While positive results have been found in the English language[4,5], the campaign's impact in non-English-speaking countries remains uncertain, even though the Movember website is available in 11 languages.

In 2019, more than 4.1 billion people worldwide had access to the internet[6]. The National Statistics Institute (INE) in Spain report that by 2019, 90.7\% of the Spanish population between 16 and 74 years had used the internet. This value drops to $63.5 \%$ for those aged 65 to 74 years[7], which is the age group in which most of the prostate cancer diagnoses occur, both in Spain and worldwide $[2,8]$, which could limit the reach of the Movember campaign.

Google is the most popular search engine in the Western World, used for $93.39 \%$ of all searches carried out in Europe and 92.18\% worldwide[9,10]. Google Trends is a free-access tool that allows users to analyze the frequency with which a term is registered in the Google search engine in relation to the total volume of searches carried out during a certain period of time and in predetermined geographical regions. These features have contributed to its use in health research as an epidemiological tool with a methodology that is yet to be standardized[11].

The objective of this study is to identify the reach and impact of the Movember campaign on the search trends seeking information about prostate cancer in the Spanish language. As Spanish has the second most native speakers of all languages worldwide[12], Google Trends offers an indirect measure of the effectiveness of the campaign.

\section{Material and Methods}

We used Google Trends (https://trends.google.es), a publicly accessible and free tool designed by Google (Santa Clara, United States). Google Trends provides information on the volume of searches on Google, which has records from 2004 onwards available; this volume is represented by the metric "RSV" (relative search volume) which is represented by a number from 0 to 100 , with 100 being the maximum search activity for the term or terms entered in the specified time.

The search was carried out on October 4, 2020, using the terms "cáncer de próstata" (from now on, "prostate cancer"), "Movember," and "cáncer de mama" (from now on "breast cancer"). Search trends from January 2009 to December 2019 were analyzed. These criteria were filtered geographically into "worldwide" and "Spain." "Pinktober" was used as a comparator as a widely recognized successful awareness campaign and to allow direct comparison with prior publications.

Google Trends provides a monthly RSV value, from which we calculated the average overall RSV, analyzing separately the months on-campaign (November for prostate cancer and October for breast cancer) and off-campaign (rest of the year).

The Joinpoint regression (JPR) model (National Cancer Institute) was used to identify significant changes in mean annual RSV (ARSV) over time for each term. The JPR model is used to better describe trends that are not constant over time, and it enables evaluation of statistically significant changes (join-points) in trends as previously described[13-16].

Linear trends in RSV were summarized using the estimated ARSV and annual percentage in change (APC). APC was used to measure differences in ARSV between 2 join-points. Average annual percentage in change (AAPC) and the respective 95\% confidence intervals were estimated to summarize linear trends in ARSV during the entire period.

The use of the natural $\log$-linear model $([\ln (y)=x b])$ enables the analysis of AAPC in rate over time. A positive value of AAPC indicates an increasing RSV (increasing search volume or interest), while a negative rate refers to a decreased interest. When a dependent variable was " 0 " a $\log (\mathrm{x}+1)$ transformation was applied to the entire dataset. A permutation test, allowing up to 4 join-points, was used to evaluate any inflection points with a significant variation in the slope of the trend. A trend was defined as "non-constant" or "constant" if slopes were identified or not identified, respectively.

Mean RSV values were compared using the Mann-Whitney $U$ test and a $P$-value $<0.05$ was considered statistically significant. The statistical analysis was performed using the statistical package SPSS v26. 


\section{Results}

Analyzing the searches between 2009 and 2019, we observed that the term "cancer de próstata" (prostate cancer) filtered "worldwide" reached the maximum RSV (RSVmax - 100) in November 2017 and the minimum RSV (RSVmin) was 38, in January 2017, the mean annual RSV (RSVmean) was 50.9 off-campaign (all months of the year, excluding November) and 78.9 on-campaign (all Novembers), observing a statistically significant increase of $35.4 \%(P<0.001)$ during the campaign months. In Figure 1a (blue lines) we can see the blue spikes of searches carried out in the months of November, which are more evident from the year 2013 onwards.

When analyzing the same strategy ("cancer de próstata," 2009 to 2019) in Spain, RSVmax was also reached in November 2017 (100) and the RSVmin (28) in December 2009. The RSVmean was 42.3 off-campaign and 51.9 on-campaign, with a statistically significant increase of $17.4 \%(P<0.001)$, these values are summarized in Table 1 and represented in Figure 1a (orange lines), showing no clear spikes in search trends in the months of November, except for the year 2017.

Regarding the term "cancer de mama" (breast cancer), filtered "worldwide" the RSVmean off-campaign and on-campaign months were 21.3 and 69.8 respectively, with an increase of $69.4 \%$ in the months on-campaign for breast cancer.

Figure $1 \mathrm{~b}$ shows how the trends in search for "breast cancer" have been increasing gradually each year during the campaign months, while trends for prostate cancer
(Figure 1a) show a minimal increase relative to breast cancer. Analyzing breast cancer filtered by "Spain," we observe an RSVmean for breast cancer of 14.5 off-campaign, and 56.5 on-campaign, with an increase of $74.3 \%$ $(P<0.001)$ during the campaign months; these results are summarized in Table 2. Figure $1 \mathrm{~b}$ shows increases of trends in searches for breast cancer in the months of October with the same trend as "worldwide," while for prostate cancer such increases are imperceptible.

\section{TABLE 1.}

Cáncer de próstata (prostate cancer), trends from January 2009 to December 2019

\begin{tabular}{|c|c|c|}
\hline & Worldwide & Spain \\
\hline RSVmax, date & $\begin{array}{c}\text { 100, } \\
\text { November } 2017\end{array}$ & $\begin{array}{c}100 \\
\text { November } 2017\end{array}$ \\
\hline RSVmin, date & $\begin{array}{c}38, \\
\text { January } 2017\end{array}$ & $\begin{array}{c}28, \\
\text { December } 2009\end{array}$ \\
\hline $\begin{array}{l}\text { RSVmean off- } \\
\text { campaign }\end{array}$ & 50.9 & 42.3 \\
\hline $\begin{array}{l}\text { RSVmean on- } \\
\text { campaign }\end{array}$ & 78.9 & 51.9 \\
\hline $\begin{array}{l}\text { RSV increase during } \\
\text { the campaign } \\
\text { months }\end{array}$ & $35.4 \%$ & $17.4 \%$ \\
\hline
\end{tabular}

RSV: relative volume of searches; $R S V$ max: maximum $R S V$; $R S V$ min: minimum $R S V$; $R S V$ mean: average $R S V$.

\section{FIGURE 1 A.}

Search trends for the term "prostate cancer"
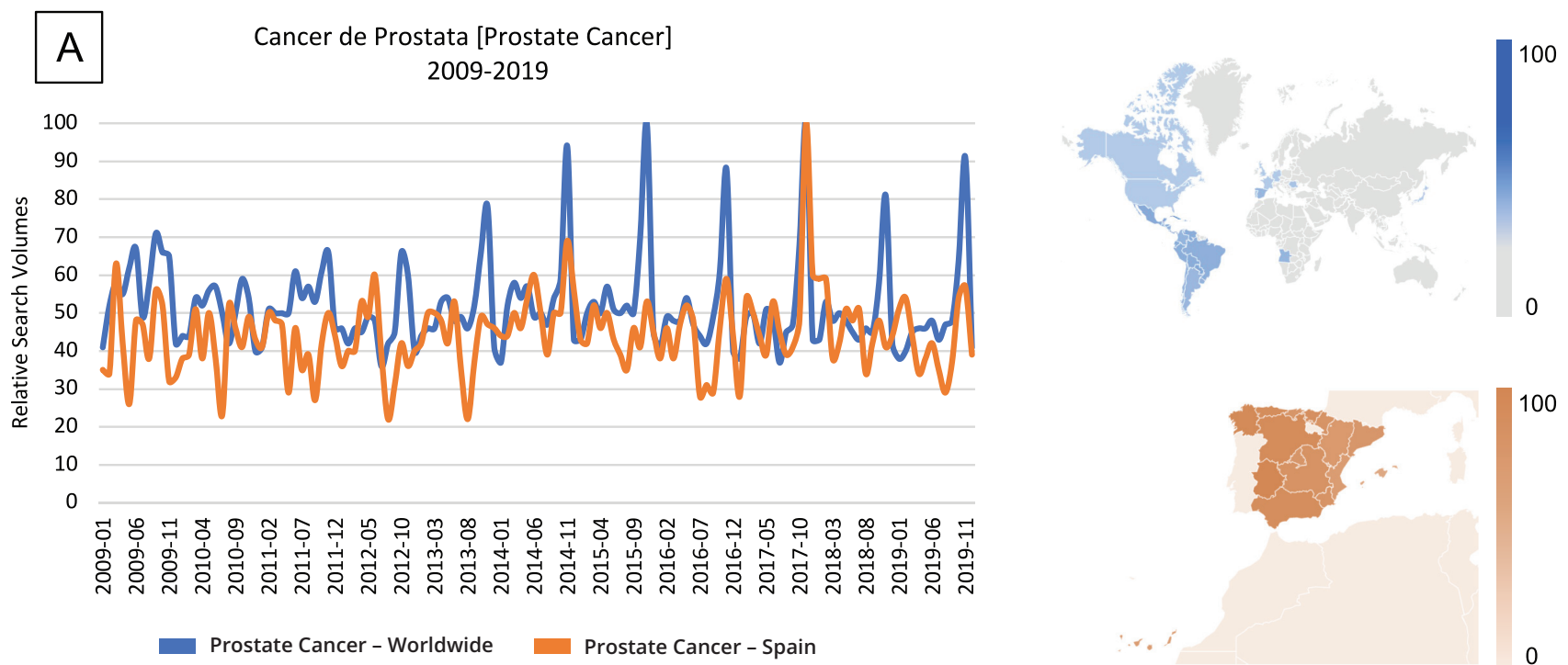
Finally, for the term "Movember" filtered "worldwide," the RSVmax was reached in November 2012 and the RSVmin (1) in multiple months over the years. RSVmean off-campaign was 3.0, while on-campaign was 43.7 with a statistically significant increase of $91.5 \%$ $(P<0.001)$. Figure 1c (blue lines) shows the spikes in search trends every November, and a virtual disappearance of searches in the rest of the year. In turn, the trend in the months of November reached its maximum in November 2012 and gradually decreased from November 2013 to November 2019 worldwide.

When analyzing the same term filtered in "Spain" (Figure 1c, orange lines) the RSVmax was reached in November 2013 and the RSVmin (1) several months over the years. RSVmean was 2.4 off-campaign and 55.9 on-campaign, with an increase of $99.2 \%(P<0.001)$. These results are summarized in Table 3.

\section{Join point regression analysis}

For the geographical region category "world," the web search for the term "cancer de próstata" (prostate cancer in English) showed a constant non-statistically significant decreasing trend (AAPC $-0.5 \%, 95 \%$ CI -1.7 to $0.7 ; P=0.4$ ) from 2009 to 2019 . The web search for "cancer de mama" (breast cancer in English) showed a non-constant increasing statistical interest trend from 2009 to 2019 (AAPC 3.8\%, 95\%CI 2 to $5.5 ; P<0.0001$ ). From 2009 to 2012 a non-statistically significant decreasing trend is seen (AAPC $-0.5 \%, 95 \% \mathrm{CI}-6.2$ to 5.5; $P=0.8$ ). Interestingly, between 2012 and 2019, a statistically significant increasing interest trend is seen (AAPC 5.7\%, 95\%CI 4 to $7.3 ; P<0.0001$ ). The web search for the term "Movember" showed a non-constant and non-statistically significant decreasing trend (AAPC $-5.4 \%, 95 \% \mathrm{CI}-17.2$ to $8 ; P=0.4$ ). A non-statistically significant increasing interest trend (AAPC 87.6\%, 95\%CI -12.1 to 300,$4 ; P=0.1$ ) from 2009 to 2011 . However, we found a statistically significant decreasing interest trend between 2011 and 2019 (AAPC -20.3\%, 95\%CI -26.6 to $-13.5 ; P<0.0001)$.

In the category for the geographical region "Spain," the web searches for the term "cancer de próstata"

\section{TABLE 2.}

Cáncer de mama (breast cancer), trends from January 2009 to December 2019

\begin{tabular}{|c|c|c|}
\hline & Worldwide & Spain \\
\hline RSVmax, date & $\begin{array}{c}100, \\
\text { October } 2019\end{array}$ & $\begin{array}{c}\text { 100, } \\
\text { October } 2013\end{array}$ \\
\hline RSVmin, date & $\begin{array}{c}12, \\
\text { December } 2012\end{array}$ & $\begin{array}{c}8, \\
\text { December } 2009\end{array}$ \\
\hline $\begin{array}{c}\text { RSVmean off- } \\
\text { campaign } \\
\text { RSVmean on- } \\
\text { campaign }\end{array}$ & 21.3 & 14.5 \\
\hline $\begin{array}{c}\text { RSV increase during } \\
\text { the campaign } \\
\text { months }\end{array}$ & 69.8 & 56.5 \\
\hline
\end{tabular}

$R S V$ : relative volume of searches; $R S V$ max: maximum $R S V$; $R S V$ min: minimum RSV; RSVmean: mean RSV.

\section{FIGURE 1B.}

Search trends for "breast cancer"
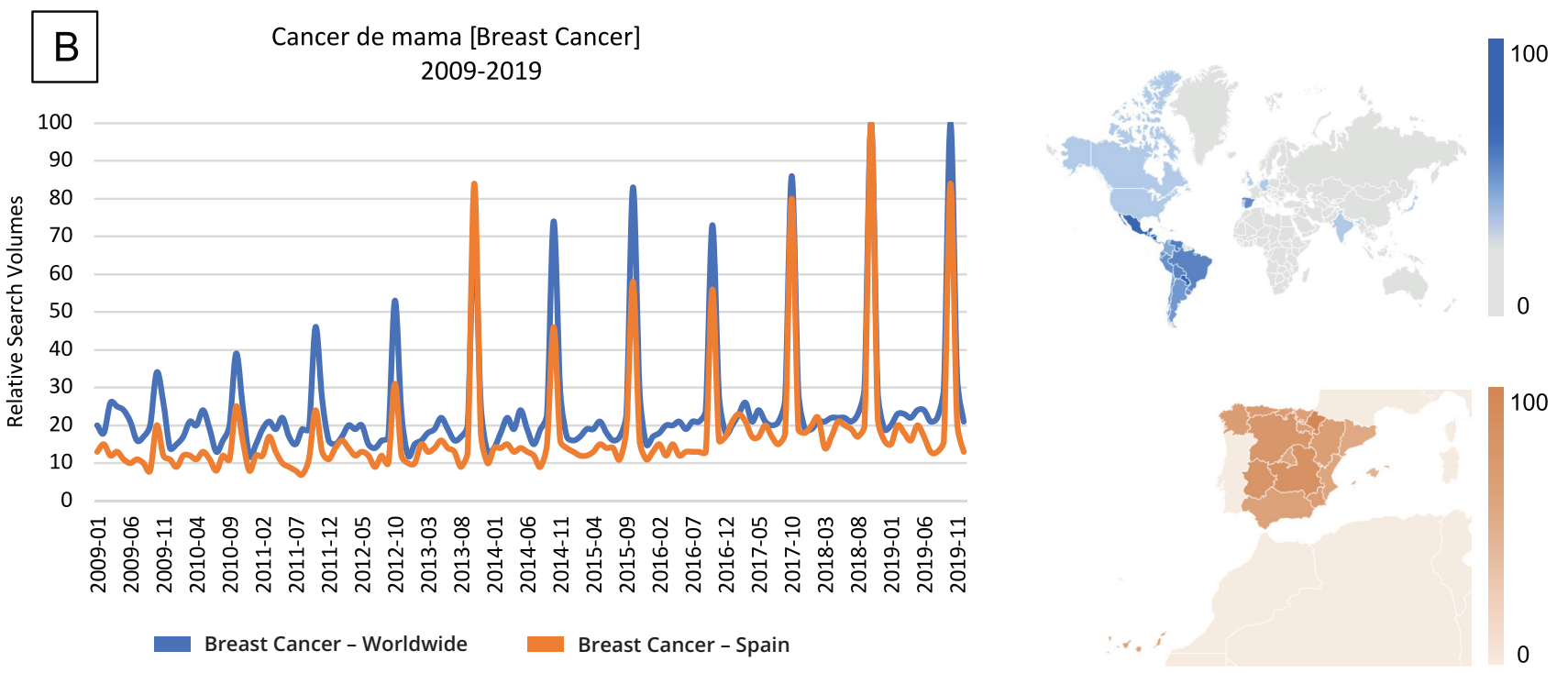


\section{FIGURE 1C.}

Search trends for the term "Movember"
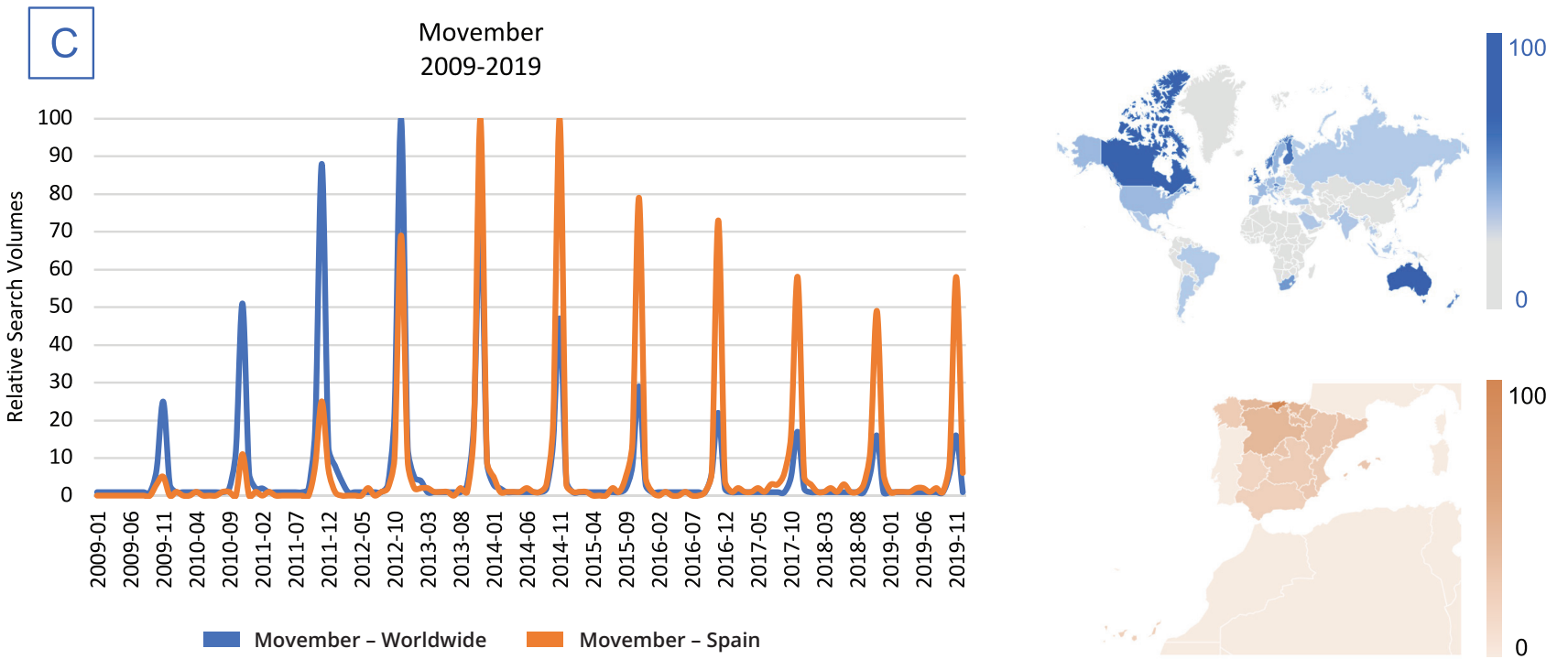

(prostate cancer in English) displayed a constant and non-statistically significant decreasing trend (AAPC $1 \%, 95 \% \mathrm{CI}-0.5$ to $2.6 ; P=0.2)$. The web searches for "cancer de mama" (breast cancer in English) showed a statistically significant increase interest trend from 2009 to 2019 (AAPC $7.8 \%, 95 \%$ CI 5.3 to $10.5 ; P<0.0001$ ). The web search for the term "Movember" showed a non-constant and statistically significant increasing trend (AAPC 24.6\%, 95\%CI 18.3 to 31.2; $P<0.0001$ ). There is statistically significant increasing interest trend (AAPC $106.3 \%, 95 \%$ CI 81.8 to $132.2 ; P<0.0001$ ) from 2009 to 2013. Nonetheless, there is evidence of a statistically significant decreasing trend between 2013 and 2019 (AAPC $-11 \%, 95 \%$ CI -16.8 to $-4.8 ; P<0.0001$ ).

\section{Discussion}

This study is the first to indirectly evaluate the impact and extent of the prostate cancer awareness campaign known as Movember in a non-English language, using the Google Trends tool. Our results show a statistically significant increase in search trends for "prostate cancer" and "Movember" during the campaigning months from 2009 to 2019, both in Spain and worldwide. Nonetheless, when directly compared with breast cancer awareness campaigns, the apparent impact is much more limited.

Further, the term "Movember" has sharp spikes in the months of November but practically disappears from search trends for the rest of the year, which makes us wonder if the Movember campaign achieves a longlasting effect or remains only a cyclic event.

Additionally, this urological awareness campaign fails to reach a strong impact on search trends when
TABLE 3.

Movember, trends from January 2009 to

December 2019

\begin{tabular}{c|c|c|}
\hline & Worldwide & Spain \\
\hline RSVmax, date & $\begin{array}{c}100, \\
\text { November } 2012\end{array}$ & $\begin{array}{c}100, \\
\text { November } 2013\end{array}$ \\
\hline RSVmin, date & 1, & 1, \\
\hline $\begin{array}{c}\text { RSVmean } \\
\text { off-campaign }\end{array}$ & several months & several months \\
\hline $\begin{array}{c}\text { RSVmean } \\
\text { on-campaign }\end{array}$ & 3.0 & 2.4 \\
\hline $\begin{array}{c}\text { RSV increase during } \\
\text { the campaign months }\end{array}$ & $91.5 \%$ & 55.9 \\
\hline
\end{tabular}

RSV: relative search volume; $R S V$ max: maximum $R S V$; $R S V$ min: minimum

$R S V$; RSVmean: average RSV.

compared with Pinktober, the breast cancer campaign. Interest in breast cancer not only remains in some form during the rest of the year but also increases year after year, both in Spain and in the rest of the world. These data are congruent with the findings of the study published by Patel et al. comparing the impact of the breast, prostate, and testicular cancer campaigns in the United States, which showed a strong increase of RSV in 
the month of October for breast cancer versus a minor increase in RSV in November for prostate cancer[17]. Similarly, Cacciamani et al. previously showed a correlation between the campaign Pinktober in the month of October and an increase in search trends for breast cancer, mammograms, and pink ribbons during this period[4].

Another relevant point is the celebrity phenomenon: a socially prominent person's disclosure that they have cancer increases public interest in that cancer. This phenomenon can generate increases in search trends greater than those produced by awareness campaigns. This was demonstrated in the cases of Angelina Jolie and Steve Jobs[18,19], and it may account for the search trends peak observed in November 2017 in Spain and worldwide following media coverage of the diagnosis of prostate cancer at 48 years of age of Latin American ex-football player Eduardo Berizzo[20].

Meanwhile, the success of the Pinktober campaign on breast cancer can be explained by its having been promoted over a longer time. Awareness campaigns on breast cancer began in 1985 with the alliance of the American Cancer Society and Imperial Chemical Industries (now part of AstraZeneca)[21]. Additionally, the early detection programs for breast cancer started in the late 1970s[22], while the equivalent in prostate cancer started in the 1990s[23], and this screening program has suffered multiple setbacks, including the recommendation against it by the US Preventive Services Task Force (USPSTF) in 2012 [24], which was maintained until the 2018 update[25].

The use of Google Trends as a tool for the indirect analysis of urological and non-urological diseases from a public health perspective has been previously addressed. Schootman et al. couldn't show a direct correlation between search trends and use of screening programs for colon, cervix, lung, breast, and prostate cancer in a state-level analysis in the United States[26]. Nonetheless, other authors have shown a positive correlation in the number of searches on cosmetic surgery modalities and the volume of procedures performed [27] or associations in search trends on sexually transmitted diseases in areas where the incidence of these is greater[28].
Our study has some limitations. First, the demographic characteristics of the population that carry out these searches are unknown. It must be considered that the campaigns intend to reach men whose age makes them candidates for programs for early detection of prostate cancer. This is recommended for the average male from the age of 50 according to the European Association of Urology[29] and from the age of 55 according to the American Urology Association[30] and the USPSTF[31]. Another limitation is the impossibility of distinguishing those individuals seeking information on prevention and early detection strategies from those already diagnosed seeking information on available treatments.

Similarly, the tools provided by Google Trends do not allow a direct comparison of the interest between different early detection strategies (mammography versus prostate-specific antigen) since the acronyms for these in English and Spanish are shared by other words from other sectors, and it is not possible to separate the results, while terms without acronyms do not yield useful results for comparison.

However, although the information derived from Google Trends does not replace formal epidemiological studies, it can be a complementary tool relevant to better understanding the scope, impact, and limitations of awareness campaigns on men's health and other public health campaigns. Overall, we found increases in search trends every November, which correlate with a positive impact of the Movember campaign in the Spanish language worldwide.

\section{Conclusion}

The prostate cancer awareness campaign "Movember" correlates with a statistically significant increase in search trends for "cancer de próstata" (prostate cancer) in the Spanish language worldwide. When compared with the breast cancer campaign "Pinktober" these increases are of a lesser magnitude but still significant. Google Trends appears to be a useful tool for indirectly assessing the effectiveness of awareness campaigns; however, other epidemiological studies are necessary to directly confirm these findings. 


\section{References}

1. Sung H, Ferlay J, Siegel RL, Laversanne M, Soerjomataram I, Jemal A, et al. Global Cancer Statistics 2020: GLOBOCAN Estimates of Incidence and Mortality Worldwide for 36 Cancers in 185 Countries. CA Cancer J Clin.2021;71:209-249. https://doi.org/10.3322/caac.21660

2. Cózar JM, Miñana B, Gómez-Veiga F, Rodríguez-Antolín A, Villavicencio $H$, on behalf of 25 Urology Units, Asociación Española de Urología.Prostate cancer incidence and newly diagnosed patient profile in Spain in 2010. BJU Int.2012;110:E701-706. https://doi. org/10.1111/j.1464-410X.2012.11504.x

3. Movember. In: Movember. https://es.movember.com/about/ foundation. Accessed 4 0ct 2020

4. Cacciamani GE, Stern MC, Medina LG, Gill K, Sotelo R, Gill IS. Cancer awareness crusades - pink ribbons and growing moustaches. Lancet Oncol.2019;20:1491-1492. https://doi.org/10.1016/ S1470-2045(19)30639-4

5. Cacciamani GE, Gill K, Gill IS. Web search queries and prostate cancer. Lancet Oncol.2020;21:494-496. https://doi.org/10.1016/ S1470-2045(20)30138-8

6. International Telecommunication Union (ITU). Measuring digital development: facts and figures 2019. https://www.itu.int/en/ITU-D/ Statistics/Pages/facts/default.aspx. Accessed 4 Oct 2020

7. Instituto Nacional de Estadistica (2019) Encuesta sobre Equipamiento y Uso de Tecnologías de Información y Comunicación en los Hogares. In: INE. https://www.ine.es/ss/Satellite?L=es_ ES\&c=|NESeccion_C\&cid $=1259925528782 \& p=1254735110672 \&$ pagename=ProductosYServicios\%2FPYSLayout. Accessed 4 0ct 2020.

8. Rawla P. Epidemiology of prostate cancer. World J Oncol.2019;10:63-89. https://doi.org/10.14740/wjon1191

9. Search engine market share worldwide. In: Statista. https://www. statista.com/statistics/216573/worldwide-market-share-of-searchengines/. Accessed 25 Jul 2020.

10. Search Engine Market Share Worldwide. In: StatCounter Global Stats. https://gs.statcounter.com/search-engine-market-share.Accessed 1 Jun 2021

11. Nuti SV, Wayda B, Ranasinghe I, Wang S, Dreyer RP, Chen SI, et al. The use of google trends in health care research: a systematic review. PLoS One.2014;9:e109583. https://doi.org/10.1371/journal.pone.0109583

12. Babbel.com, GmbH LN The 10 Most Spoken Languages In The World. In: Babbel Magazine. https://www.babbel.com/en/magazine/the-10most-spoken-languages-in-the-world. Accessed May 4, 2021.

13. Cacciamani GE, Dell'Oglio P, Cocci A, Russo GI, De Castro Abreu A, Gill IS, et al. Asking "Dr. Google" for a second opinion: The devil is in the details. Eur Urol Focus.2019;7(2):479-481. https://doi.org/10.1016/j. euf.2019.10.011.
14. Cacciamani GE, Bassi S, Sebben M, Marcer A, Russo GI, Cocci A, et al. Consulting "Dr. Google" for prostate cancer treatment options: a contemporary worldwide trend analysis. Eur Urol Oncol.2019; https:// doi.org/10.1016/j.euo.2019.07.002

15. Cacciamani GE, Sebben M, Tafuri A, Nassiri N, Cocci A, Russo Gl, et al. Consulting "Dr. Google" for minimally invasive urological oncological surgeries: a contemporary web-based trend analysis. Int J Med Robot.2021;17:e2250. https://doi.org/10.1002/rcs.2250

16. On behalf of EAU-YAU Men's Health Working Group, Russo GI, di Mauro M, Cocci A, Cacciamani GE, Ciminio S, Serefoglu EC, et al. Consulting "Dr Google" for sexual dysfunction: a contemporary worldwide trend analysis. Int J Impot Res.2019; https://doi. org/10.1038/s41443-019-0203-2

17. Patel MS, Halpern JA, Desai AS, Keefer MK, Bennett NE, Brannigan RE. Success of prostate and testicular cancer awareness campaigns compared to breast cancer awareness month according to internet search volumes: a Google Trends analysis. Urology.2020; https://doi. org/10.1016/j.urology.2019.11.062

18. Ayers JW, Althouse BM, Noar SM, Cohen JE. Do celebrity cancer diagnoses promote primary cancer prevention? Prev Med.2014;58:8184. https://doi.org/10.1016/j.ypmed.2013.11.007

19. Kaleem T, Malouff TD, Stross WC, Waddle MR, Miller DH, Seymour $A L$, et al. Google search trends in oncology and the impact of celebrity cancer awareness. Cureus.2019;11:e5360. https://doi.org/10.7759/ cureus. 5360

20. Pineda R. Eduardo Berizzo sufre cáncer de próstata. El País.2017. Available at: https://elpais.com/deportes/2017/11/22/actualidad/ 1511307800_068768.html. Accessed September 27, 2021.

21. A brief history of breast cancer awareness month. 2019. In: Brevard Health Alliance. Available at: https://www.bhachc.org/a-brief-historyof-breast-cancer-awareness-month/. Accessed November 8, 2020.

22. Bleyer A, Welch HG. Effect of three decades of screening mammography on breast-cancer incidence. N Engl J Med.2012;367:1998-2005. https://doi.org/10.1056/NEJMoa1206809

23. History of ACS Recommendations for the Early Detection of Cancer in People Without Symptoms. https://www.cancer.org/health-careprofessionals/american-cancer-society-prevention-early-detectionguidelines/overview/chronological-history-of-acs-recommendations. html. Accessed November 9, 2020.

24. Moyer VA, U.S. Preventive Services Task Force. Screening for prostate cancer: U.S. Preventive Services Task Force recommendation statement. Ann Intern Med.2012;157:120-134. https://doi. org/10.7326/0003-4819-157-2-201207170-00459 
25. Fenton JJ, Weyrich MS, Durbin S, Liu Y, Bang H, Melnikow J. Prostatespecific antigen-based screening for prostate cancer: evidence report and systematic review for the US Preventive Services Task Force. JAMA.2018;319:1914-1931. https://doi.org/10.1001/jama.2018.3712

26. Schootman M, Toor A, Cavazos-Rehg P, Jeffe DB, McQueen A, Eberth J, et al. The utility of Google Trends data to examine interest in cancer screening. BMJ Open.2015;5:e006678-e006678. https:// doi.org/10.1136/bmjopen-2014-006678

27. Tijerina JD, Morrison SD, Nolan IT, Parham MJ, Nazerali R. Predicting public interest in nonsurgical cosmetic procedures using Google Trends. Aesthet Surg J.2019; https://doi.org/10.1093/asj/sjz264

28. Johnson AK, Mehta SD. A comparison of Internet search trends and sexually transmitted infection rates using Google trends. Sex Transm Dis.2014;41:61-63. https://doi.org/10.1097/0L0.0000000000000065
29. Mottet N, Bellmunt J, Bolla M, Briers E, Cumberbatch MG, De Santis $\mathrm{M}$, et al. EAU-ESTRO-SIOG Guidelines on prostate cancer. Part 1: screening, diagnosis, and local treatment with curative intent. Eur Urol.2017;71:618-629. https://doi.org/10.1016/j.eururo.2016.08.003

30. Carter HB, Albertsen PC, Barry MJ, Etzioni R, Freedland SJ, Greene $\mathrm{KL}$, et al. Early detection of prostate cancer: AUA Guideline. J Urol.2013;190:419-426. https://doi.org/10.1016/j.juro.2013.04.119

31. US Preventive Services Task Force, Grossman DC, Curry SJ, Owens DK, Bibbins-Domingo K, Caughey AB, Davidson KW, et al. Screening for prostate cancer: US Preventive Services Task Force Recommendation Statement. JAMA.2018;319:1901-1913. https://doi.org/10.1001/ jama.2018.3710 